\title{
SIMULATION THINKING: WHERE DESIGN AND ANALYSIS MEET
}

\author{
Mary Kathryn Thompson \\ 373-1 Guseong-dong Yuseong-gu \\ KAIST Dept. of Civil and Env. Eng. \\ Daejeon, 305-701, S. KOREA
}

\begin{abstract}
Design and analysis have historically been viewed as opposites. However, design and analysis are closely related activities which involve similar types of thinking. This work examines the similarities and differences in cognition and education for design and numerical simulation. The educational pedagogy and educational outcomes of a first year design program and a graduate level finite element analysis course are discussed, and a list of characteristics and cognitive abilities of a good simulator - dubbed "simulation thinking" - is presented.
\end{abstract}

\section{INTRODUCTION}

Design and analysis have historically been viewed as opposites. Analysis involved the decomposition of existing components or systems to better understand their behavior (and flaws), while design was considered a synthetic activity that created new components or systems. The ways that design and analysis have historically been taught have also been opposites. Design was treated as a creative, intuitive, and experience based activity, which for all intents and purposes, could not be taught. It could only be learned by doing. In contrast, courses in engineering analysis (including those which focus on simulation) have been heavily steeped in mathematics. But it seems that the true nature of both areas lies somewhere in the middle.

Design and analysis are related activities which combined constitute the majority of engineering activities. Unsurprisingly, they require related types of thinking and can be taught in similar ways. This work examines the similarities and differences in education for design and numerical simulations (finite element analysis) with a special emphasis on the related goals, processes, and cognitive activities.

\section{A BRIEF HISTORY OF DESIGN EDUCATION}

Design education has undergone several major transformations in the past century. In the early part of the 20th century, design was taught as an art or trade. Experience was heavily emphasized. Drafting and drawing were key technologies that all students were required to master. In the 1950s, the so-called Grinter report (1956) prompted a wide scale shift in engineering education away from engineering practice and towards engineering science. It was thought that students required a solid foundation in the fundamentals of mathematics and science before they could begin their engineering education.

The backlash began immediately. As early as the 1960s, engineering faculty began to notice a "lack of understanding of design by their students" and first year design programs began to appear in the 1970s and 1980s. (Sheppard and Jenison 1997) The 1990s saw a new dawn of freshman design experiences prompted by concerns about and an improved understanding of engineering enrollment attrition (Seymour and Hewitt 1994) and aided by calls for improved engineering design education from the US National Science Foundation (NSF 1990) and other researchers (Beitz 1994).

The 1990s and 2000s also saw a major push towards the development of design as a science and as a rigorous field of its own. New design theories, including Suh's Axiomatic Design Theory (1990) were developed, and a number of influential texts were written including (Pahl and Beitz 1995).

\subsection{Design Thinking}

The 2000s saw the emergence of 'design thinking' in discussions about design and design education. Design thinking was proposed in contrast to and as a counterpart of analytical thinking and was part of the larger effort to treat design as its own subject. Steven $\mathrm{Lu}$ (2007) defined design thinking as "a set of mind-sets and basic principles that guides designer's synthesis- 
based thought processes in the creation of functional and purposeful technical articles." He adds: "Design thinking is not about any specific design theory or methodology; but rather a prerequisite (or perspective) for the correct study and effective practice of engineering design." Thus, design thinking represents the abilities and characteristics of a good designer, and the abilities that faculty should strive to develop in their students.

One of the most complete discussions of design thinking can be found in (Dym et al. 2005). The paper's definition of good design thinking includes: divergent-convergent thinking; systems thinking; the ability to tolerate ambiguity and uncertainty; the ability to estimate; the ability to make decisions; the ability to conduct experiments; the ability to work in teams; and the ability to think and communicate in the multiple languages of design.

$\mathrm{Lu}$ (2007) added: "synthetic (rather than analytical) thinking; functional (rather than physical) thinking; system (not component) thinking; top-down (not bottom-up) thinking; constructionist (rather than determinist) thinking; solution-neutral (rather than solution-specific) thinking; demand-driven (rather than supply-based) thinking; want-pull (rather than need-push) thinking; price-based (rather than cost-based) thinking; [and] socio-technical (rather than pure-technical) thinking."

\section{SIMULATION EDUCATION}

Modern numerical simulation had a much later start than engineering design. The first step towards modern finite element analysis was proposed by a mathematician named Richard L. Courant in 1943. The credit for more general numerical simulation goes to Turner et al. (1956). But practically speaking, numerical simulation didn't get its start until the 1970s when the growth of computers made large scale computation possible. In the past 40 years, the field has grown as quickly as the available computational power has permitted and leaped from engineering to urban planning, finance, and a host of other diverse fields, taking analysis to a whole new level.

Simulation education followed the progress in industry in an attempt to prepare the next generation of engineers for the information age. Courses in simulation have taken two basic approaches. Some courses and texts, especially those offered by industry and for professionals in industry, focus on training engineers to use simulation software. They frequently offer stepby-step instructions and tutorials. They assume substantial knowledge and experience on the part of the student about the problem to be solved and engineering problem solving in general. Courses in academia, especially at the graduate level, often take the opposite approach and focus heavily on the mathematic basis for numerical simulation. Students learn about the assumptions which are contained within commercial simulation programs and frequently learn to program their own simulations. However, actually running commercial simulation software is usually left up to the individual student to learn on their own time.

Courses and texts that take the middle ground and focus on making the engineering assumptions and decisions that are involved in setting up, running, estimating and evaluating the results of a numerical simulation - what could be referred to as 'simulation thinking' - are few and far between.

\section{WHERE DESIGN MEETS ANALYSIS}

Design and analysis have a long history of being separated from each other within academia. Dym et al. (2005) note that 'design' faculty are "often segregated from 'analysis' faculty by the courses they teach." Sheppard (2001) notes that recent advances in engineering design research and education "make the dichotomy and perhaps incompatibility of how engineering design and engineering analysis courses are taught more apparent." But design and analysis are not opposite ends of the spectrum. They are more like two sides of the same coin. Or, perhaps more fittingly, they are two tools in an engineering toolbox - intended to be used at different times and in different ways to address aspects of the same problem.

\subsection{Design Requires Analysis (and Simulation)}

There is no question that design requires analysis. In the early stages of design, a substantial amount of information must be analyzed before the the design specifications and functional requirements can be defined. These activities can include: root cause analysis to ensure that the designers are trying to solve the correct problem; data analysis of the results from customer surveys, user observations, and other types of stakeholder research; and the reverse engineering (literally, analysis via decomposition) of existing products during benchmarking activities.

Analysis also appears in later stages of the design process. Once multiple concepts have been generated, some type of analysis must be performed to determine the relative merits of each design and to choose one or more for continued development. This can include hand calculations, numerical simulations, experiments, and more. Design optimization also requires analysis. During the optimization process, models of the new design's behavior are created and used to determine (predict) the effect of changing various design parameters until the best (or at least acceptable) combination of parameters is determined. 


\section{Thompson}

Of course, analysis can appear anywhere in the design process and take on any form. The type of analysis performed must be tailored to meet the demands of the current state of the design. Figure 1 shows one possible interpretation of the interactions between the design, analysis, and research domains within engineering.

\begin{tabular}{|c|c|c|c|c|}
\hline$\underline{\text { Design }}$ & & Analysis & & Research \\
\hline Identify Problem & $\Leftrightarrow$ & $\begin{array}{l}\text { Analyze Problem and } \\
\text { Existing Solution(s) \& } \\
\text { System(s) }\end{array}$ & $\Leftrightarrow$ & Identify Problem \\
\hline $\mathfrak{l}$ & & $\sqrt{3}$ & & $\sqrt{2}$ \\
\hline Define & & Understand/Predict & & Investigate \\
\hline $\begin{array}{l}\text { Requirements / } \\
\text { Specifications }\end{array}$ & 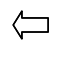 & $\begin{array}{c}\text { System / User } \\
\text { Behavior }\end{array}$ & $\Leftrightarrow$ & $\begin{array}{l}\text { Natural and } \\
\text { Scientific }\end{array}$ \\
\hline ת & & & & $\begin{array}{l}\text { Phenomena, } \\
\text { Consumer/ }\end{array}$ \\
\hline $\begin{array}{l}\text { New Conceptual } \\
\text { Designs }\end{array}$ & $\Rightarrow$ & $\begin{array}{c}\text { Analyze New } \\
\text { Information / Designs }\end{array}$ & $\Leftrightarrow$ & $\begin{array}{l}\text { User Behavior } \\
\text { \& Preferences, } \\
\text { etc. }\end{array}$ \\
\hline Detailed Design & 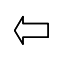 & Select Best Design & & \\
\hline 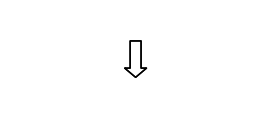 & 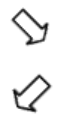 & Optimize & & ת \\
\hline $\begin{array}{l}\text { New Technology, } \\
\text { Product or Knowledge }\end{array}$ & & New Knowledge & & New Knowledge \\
\hline
\end{tabular}

Figure 1: Engineering Activities Shift Between Domains

\section{2 ‥ But Designers Don't Like to Do Analysis (or Simulation)}

Unfortunately, student designers prefer not to do analysis if they can avoid it. Sheppard's work (2001) "strongly suggest[ed] that there are a number of analysis-type activities that design engineers engage in." But she also noted that "many upperdivision engineering students become frustrated when they attempt to apply the formal analytical models they learned in their 'fundamentals' classes to verify or direct design decisions." She hypothesized that some of the frustration might be due to an inability "to create a map between complex and/or incompletely defined situations [commonly found in design]... and simplified analysis models they have learned." She suggested that students may totally discount the value of simplified analytical models once the students realize that the models "account for only a subset of relevant factors." She also thought that students may not "recognize the need for 'qualitative analysis procedures' and 'analytical reasoning' throughout the design and development process," or simply may not have enough time to do so.

\subsection{Analysis in a First Year Design Class}

Similar trends have been observed in a required first year design course at KAIST where teams of 4 - 6 freshmen work together on 16 week long design projects (Thompson 2009a; Thompson 2009b). The course offers a wide variety of design projects which cover everything from robotics and aeronautics, to policy and educational design. At the end of the semester, the students are required to provide some sort of evidence that their project will be technically, socially, and economically successful. They can demonstrate the technical viability in a number of ways including: calculations, simulation, and prototyping.

In the past three semesters, only 36 out of 244 teams (14.8\%) included any type of numerical analysis in their final papers (Table 1). Most of these examples were simple calculations to help with design decisions (component geometry, material selection, etc.) or to verify that the design would work (calculate resource consumption and efficiencies, etc.) 


\section{Thompson}

There seems to be little correlation between the presence of analysis in the final project and the students' project advisor with two exceptions. Every biofuel from organic waste team ( 7 teams over 2 semesters) and all but one eco-friendly air conditioner team (4 out of 5 during 1 semester) included some type of analysis in their project. These two professors accounted for $29 \%$ of the projects with analysis. No other professor had more than 2 projects with analysis over the 3 semester period.

However, there seems to be a strong correlation between the presence of analysis in the final report and the semester in which the class is taken. When the course was taught with first semester students, approximately $8 \%$ of the teams included some type of analysis in their projects (8.8\% in Spring 2008 and 7.6\% in Spring 2009). When the course was taught with second semester students, that number jumped to $27.1 \%$.

Only 3 teams over the past three semesters included any type of simulation. One team used commercial finite element software to calculate the stresses in an air-drop vaccine container. A second team created a numerical model to determine the reflection of a beam of light within a stream of water exiting a toy water gun. A third team created a 3D model with incident light and shadows to help calculate the incident solar energy on a novel eco-friendly office building. All three teams were composed of second semester freshmen.

Table 1. Prevalence of Analysis in First Year Design Projects

\begin{tabular}{|c|c|c|c|}
\hline Semester & Projects with Analysis & Total Projects & $\%$ Total \\
\hline Spring 2008 (1st semester) & 7 & 80 & $8.8 \%$ \\
\hline Fall 2008 (2nd semester) & 23 & 85 & $27.1 \%$ \\
\hline Spring 2009 (1st semester) & 6 & 79 & $7.6 \%$ \\
\hline Total & 36 & 244 & $14.8 \%$ \\
\hline
\end{tabular}

None of the first year students seemed to have any major difficulties with doing the statistical analysis for the stakeholder research (surveys, focus groups, etc.) or with concept selection.

\subsection{Discussion}

The situation for first year students is different than for upperclassmen. The freshmen have had few or no engineering classes and have minimal knowledge about mechanics and strength of materials, heat transfer, optics, and more. Many have no experience with numerical simulation. Nevertheless, we have seen little or no evidence during freshman design reviews and other discussion with students that they do not value analysis or believe that simplified models are of limited value. Some of our students genuinely do not see the need for analysis, simulation, or any other type of proof that their final design will work. For those students, design is seen as a purely creative activity not to be marred by any unpleasant intrusion of reality. (We do our best to dispel that illusion.) But the majority of students avoid analysis because of a perceived lack of time or sufficient subject-specific knowledge. The students have both the time and knowledge to do some first order calculations. (The student teams who did perform some type of analysis mostly limited themselves to back of the envelope calculations.) They also have substantial background research and a strong support network of faculty members and TAs to help with calculations. Their hesitation to engage in any type of analysis seems to be due to a lack of confidence combined with a misconception that analysis is a complicated activity that requires an inordinate amount of time and extensive training. This is supported by the fact that many teams that did not perform any type of analysis promised to return to their projects in a few years when they knew more about their major.

\section{WHERE SIMULATION MEETS DESIGN}

Initially it may seem strange to view simulation as a type of design activity. But in many ways the analyst who sits down to a commercial finite element package is no different than a painter. The analyst is immediately greeted with a blank screen surrounded by dozens - sometimes hundreds - of buttons, menus, and options. The painter sits down to a newly gessoed canvas with piles of oil paint tubes, brushes, knives, and assorted other tools on either side. For both, the possibilities are nearly endless. And for novices in either field, this can be petrifying. The fundamental difference between the painter and the engineering student is that the painter has been well prepared to start a new project from scratch. The engineer has not.

In most engineering courses, students are given well defined problems (given this, find that) to solve. All of the assumptions and simplifications have been made for them. The goal is clear and the success metrics are already defined. The primary task of the student is to set up the equations and solve them. The professor evaluates the results and typically assigns a grade based on the answer.

Numerical simulation inverts this process. To perform a numerical simulation, the student or analysts must identify the problem, make the simplifications and assumptions, and set up the model. The computer typically sets up the equations and 


\section{Thompson}

solves them. The student, then, must look at the results, assess their accuracy and quality, and determine if more work is needed. If anything, the role of the student begins to look more and more like that of a designer (Table 2.)

Table 2. Comparison of Simplified Design and Analysis Processes

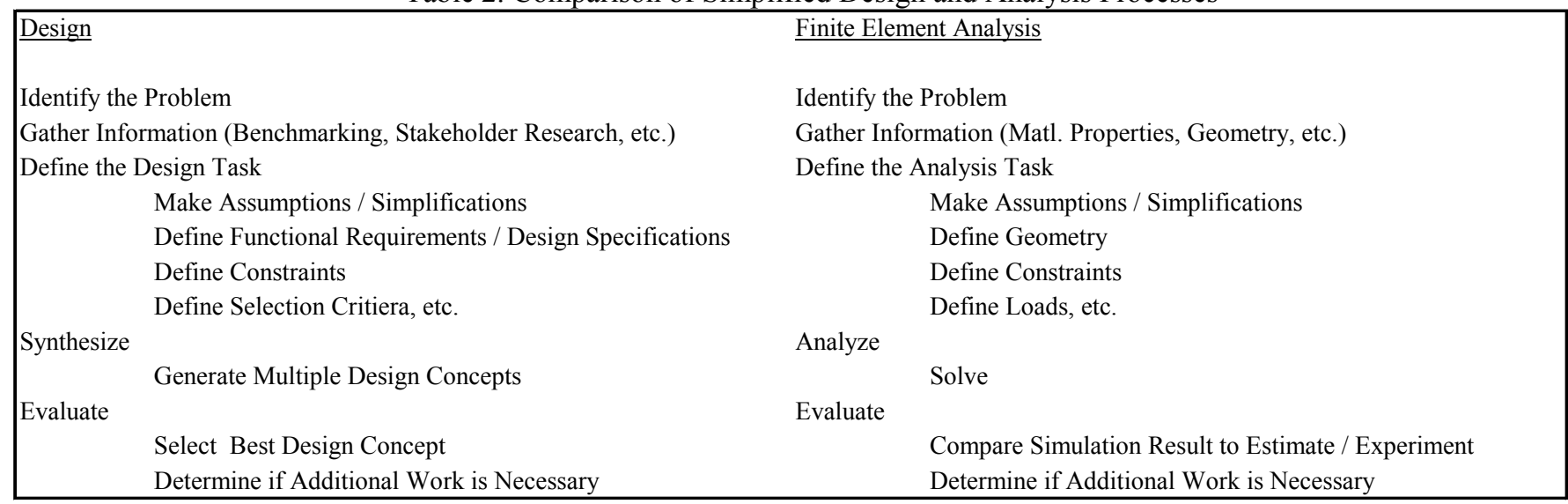

\section{SIMULATION EDUCATION VS. DESIGN}

If design and simulation share similar procedures, then it stands to reason that design and simulation courses would also share certain characteristics. To explore the relationship between design and simulation education, the results of two finite element simulation classes were examined.

\subsection{Course Descriptions}

The first class was a one week (40 hour) not-for-credit graduate level seminar entitled: "Introduction to ANSYS and Finite Element Applications.” It was offered at MIT each January from 2004 - 2007 by. M. K. Thompson and Dr. John M. Thompson. The course was originally intended to improve finite element software training. Commercial FEA short courses provided more information than engineers from industry could process, but still left their students unable to use the program without step-by-step instructions. Rather than trying to teach the students everything that there was to know about the program, Intro to ANSYS focused on the process of setting up and running a finite element simulation. Heavy emphasis was placed on the assumptions and decisions that were made when creating a new finite element model. Every exercise included some type of verification to show that the results of the simulation met expectations and matched the analytical solution or experimental data. Tutorial exercises became increasingly complicated and fewer instructions were provided as the course went on. This was done to remove the students" "training wheels" and allow them to gain confidence in running the program independently. Students were also introduced to the program documentation so they could continue to teach themselves after the seminar ended.

Over the four year period, 65 students from 11 department including engineering, architecture, business, and the natural sciences finished the course. The course was primarily for graduate students $(83 \%)$, but some undergraduates also attended. The majority of the students were doctoral candidates. Roughly half (45\%) had previous experience with finite element analysis. A survey was conducted at the end of each program.

The second course was a 3 unit, 6 week (48 hour) graduate level course on "Engineering Analysis." The course was offered by Dr. John M. Thompson (co-taught with M. K. Thompson) as a part of the KAIST International Summer School program. The course included much of the material from Intro to ANSYS, but also included more general information on estimation (Fermi problems), finite element theory, boundary value problems, and more. 11 students from 3 departments (civil engineering, mechanical engineering, and material science) attended. All were master's candidates with little or no previous experience with finite element analysis. No final survey was conducted.

\subsection{The Need for Real Projects}

Several trends were observed in both simulation courses. First, the success of the students seemed to depend strongly on whether or not they had a real and immediate problem to solve which required the course material. In the first course, roughly $40 \%$ of the students $(27 / 65)$ said that they took the course to work on a specific research problem. All of the students in the second course also required the course material for their research, although they tended to be in much earlier stages of their 


\section{Thompson}

research and had developed less intuition about their problems. Students who did not have a specific research problem, including most of the undergraduate students, had a much harder time with the course. This was reflected in an extremely high attrition rate for the undergraduate students.

It is clear that students in a finite element applications course benefit from having an immediate application for the course material. The students, themselves, also recognized this. In one of the course evaluations, a student suggested: "Students should come to class with a unique research problem in mind. Some time each day should be spent developing those unique problems using what we learned the day before."

Interestingly, this reflects what design professors have known for years: students learn highly abstract, process-based material better if they have an immediate need to apply what they are learning to a real problem. Project topics do matter: thought experiments and other contrived problems do not elicit the same level of learning. As a result, more and more design courses have adopted partnerships with industry to ensure that their students have a stable pool of real problems to work on.

This strengthens the ties between design and simulation education. It also suggests that simulation courses may benefit from taking a similar approach by including semester long projects from research or industry.

\subsection{Trial and Error is a Problem}

One of the greatest difficulties that students have in finite element analysis seems to be in choosing elements and setting up the boundary conditions. Commercial finite element packages do, to some degree, encourage trial and error behavior. After all, there are a limited number of elements available to the user, a limited number of constraints that are available to each element, and a limited number of ways in which the constraints can be applied. The programs will often also helpfully inform the user if a model if over or under constrained. As a result, simulation students will often eschew reading the documentation to help them understand the assumptions built into each element and skip thinking about their problem to determine the correct boundary conditions. Instead, they plunge into the using software on the assumption that incorrect decisions will eventually be made clear to them. In effect, they leave the thinking to the computer and their results to chance.

Design students are no different. They frequently jump right into building a prototype without really thinking about their problem or considering alternative solutions. They assume that their ideas will eventually be validated (or refuted) by the prototype without the pesky effort of having to actually design something.

In design courses, this type of behavior can be minimized by requiring students to submit detailed documentation which explains their design thought process and the details of the prototype that they wish to build before giving them permission or lab access to proceed. Downplaying the role of build-and-test in the course can also help. Similarly, requiring simulation students to submit plans that include all of the assumptions that will go into their models, including element choice and boundary conditions, before sending them off to input that information into the computer forces the students to think about their problem. (It also sometimes results in annoyed students.)

The trial-and-error phenomenon in design is different from the one that we see in simulation. But the fact that it is prevalent in both fields and is strongly linked to an attempt to avoid independent thought indicates a larger problem within engineering education.

\subsection{Algorithmic Thinking and Learning is Also a Problem}

Some of the prevalence of trial and error in simulation may be due to a bias towards algorithmic learning in primary and secondary education. During the KAIST Engineering Analysis course, one student was working on a project to simulate the thermal-mechanical response of a square plate to an incident laser beam. Several months after the course, the same student returned to ask how to set up the boundary conditions for the same problem in a cylindrical coordinate system. Although the new model was nearly identical to the old one, the student had no examples in cylindrical coordinates to follow and was unable to proceed on his own.

The situation is unsurprising. Much of the mathematical education that students received in middle school and high school involves solving problems by example. Algorithmic learning is deeply ingrained in engineering students before they enter university and results in a type of learned helplessness in the absence of examples. It can be very difficult to get students to learn to think axiomatically and to derive their solutions or determine their actions based on first principles instead.

\subsection{Absolute Faith in Technology: Prevalent but Unrealistic}

Sometimes simulation students seem to have a strong, but unrealistic faith in the technology that they are using. Commercial finite element programs may calculate solutions to six decimal places. Students will assume that those answers are good to six decimal places, even if their material properties aren't even good to one decimal place. Left to their own devices, they will assume that their simulation results are valid without comparing them to an estimate, analytical solution, or experimental results. They often fail to recognize that their results are only as good as the assumptions that they included in the model. 


\section{Thompson}

Design students, similarly, have tremendous faith in the fact that their designs will work. As a result, many design class projects (and even research projects!) only work properly once or twice. This is long enough to compete in a design competition or get video and photos for a thesis, but not enough to be a viable technology or product.

Both Intro to ANSYS and the Engineering Analysis course strongly emphasized the adage: Garbage In = Garbage Out. Design courses frequently emphasize robustness and devise design contests that require repeated or continued operation. Nevertheless, students' absolute faith in technology can be difficult to shake.

\section{DESIGN THINKING AND SIMULATION}

The last three cases discussed above shared a common theme: difficulty on the part of the students to engage in independent thinking or a tendency to engage in biased or misdirected thinking. The discussion in the academic design community about 'design thinking' was motivated, in part, by similar behavior observed in design students and a desire to improve design education. Thus, a similar set of mind-sets - 'simulation thinking' - may be helpful in improving simulation education. If so, to what degree would the two sets overlap?

\subsection{What Doesn't Apply?}

Clearly, some aspects of design thinking will not apply to simulation. The view of design and analysis as opposites, while not entirely true, is not without some justification. Simulation thinking is, by definition, more analytic than synthetic and more determinist than constructionist, even if simulation does require constructing (synthesizing) models for the purposes of deterministic analysis. Similarly, simulation relies heavily on convergent thinking and has little need for truly divergent thinking.

\subsection{What Applies to Education in General?}

The ability to work in teams was cited by Dym et al. (2005) as one aspect of design thinking, based partly on the argument that "to an increasing degree, design is being recognized and taught as a team process with multiple socio-technological dimensions." They also mentioned that design is "inherently argumentative" and involves "negotiation." However, both design and analysis can be solitary activities, or can involve huge groups of people scattered across multiple time zones. The motivation for increased team work in engineering programs is due, in part, to the changing nature of the engineering industry and the world in general. Team work should not be limited to design, or even engineering. It is a fundamental soft skill that should be included in all education. For this reason, team work should not be included in simulation thinking, but rather classified as a skill for general education.

Similarly, critical thinking should be part of a general education for all students.

\subsection{What Applies to Engineering in General?}

Dym et al. (2005) identified the ability to communicate in the "several languages of design" as a component of design thinking including: verbal communication, graphical communication, shape grammar, mathematics or analytical models, and numbers (part dimensions, parameters, etc.). Certainly, it is an important skill, but designers are not limited to interacting with other designers. They need to communicate to customers and clients, to manufacturing engineers, and even to the analysts who performed related simulations. The several languages of design are, in fact, some of the languages of engineering. All engineers need to be able to read documents, part drawings, and blue prints. They need to be equally comfortable with numbers and figures. So it may be better to reclassify this skill as "the ability to communicate in the various languages of engineering" and include it for all engineers.

Similarly, the ability to make engineering decisions, the ability to make engineering estimates, the ability to tolerate ambiguity and uncertainty, and the ability to conduct scientific experiments should all be included for all engineers.

\subsection{Systems Thinking}

Systems thinking in design was developed to address the increasing complexity in modern designs. Systems thinking tries to help the designers place their work into the context in which the artifact will function.

Analysts, by nature, tend to exclude as much of the outside world from their simulations as possible to reduce the time and computational power required. But that doesn't mean that the outside world is ignored. Instead, simulation models are connected to the world around them through the careful choice of boundary conditions. Since the choice of boundary conditions can be very difficult for simulation students, it is possible that introducing a type of systems thinking could also be beneficial for simulation education. 


\subsection{Getting the Problem Definition Right}

A number of elements in design thinking, including divergent-convergent, functional, top down, solution neutral, demand driven, price based, want / pull, and socio-technical thinking are not strictly applicable to simulation, yet they all share a common purpose. Each of these characteristics or abilities helps the designer clarify the design problem or task. For designers, this means identifying the 'real' problem and properly defining the design specifications, constraints, selection criteria, and success metrics. "No sooner has a client or professor defined a series of objectives for a designed artifact than the designers - whether in a real design studio or a classroom - want to know what the client really wants. What is a safe product? What do you mean by cheap? How do you define the best? Questioning is clearly an integral part of design." (Dym et al. 2005) How much questioning must be done depends on both how specific the original request is and how open the client is to temporarily expanding the boundaries of the problem to ensure that it is the correct problem to solve. But a good designer rarely accepts the problem as-given. They question until the true problem is found.

Analysts, too, need to ensure that they are solving the correct problem. It is their responsibility to communicate with experts and clients and learn enough about the problem to be sure that the simulation will yield accurate and valuable results. While the detailed aspects of design thinking that lead the designer to the correct problem definition are not applicable to simulation, the ability to identify the 'real' problem is common to all of engineering.

\subsection{What's Missing?}

Although many aspects of simulation thinking have been discussed above, it seems that four key aspects of simulation thinking are missing from the previous discussion of design thinking. They are the:

- Ability to make assumptions and simplifications

- Ability to recognize assumptions and simplifications that others have made

- Ability to evaluate assumptions and results (i.e. to engage in critical thinking)

- Ability to handle compromise

Just as aspects of design thinking applied to simulation thinking, these aspects of simulation thinking could apply to design. However, they likely apply more to simulation thinking than design. The one exception to this is the ability to handle compromise. In simulation, compromise is always necessary. A fundamental conflict exists between model size and accuracy and the time and computational power required to solve it. The analyst must make assumptions and simplifications to obtain the best answer for a reasonable cost. In design, however, many major design theories including Axiomatic Design (Suh 2001) and TRIZ (Altschuller 2005) urge designers to reject compromise. Instead, they recommend that designers actively seek out and eliminate coupling and conflict to reduce complexity and improve performance whenever possible. Thus, good design thinking should include the ability to resist compromise until absolutely necessary.

\subsection{Summary}

Table 3 includes a summary of various types of skills, mind-sets, and 'thinking' based on the discussion in Section 7. It includes a reclassification of the elements of design thinking discussed in this work. It also includes the new elements of simulation thinking proposed in Section 7.6.

\section{$8 \quad$ ISN'T IT ALL JUST ENGINEERING?}

In the end, perhaps the issue is academic. Does it matter what activities we classify as requiring 'design thinking' versus those which involve 'simulation thinking'? Does anyone really benefit from the distinction or are we simply strengthening artificial boundaries which have been placed upon our field? All engineers should be able to do both design and analysis, to look at problems from both perspectives, and use the tools, techniques, and thought processes from both disciplines when needed. We, as individuals, are not constrained by labels. Our thinking should not be either.

\section{CONCLUSIONS}

This work examined the relationship between design and analysis. It was shown that design requires analysis, and that aspects of design can be found within simulation, but that students in both design and simulation courses seemed to have difficulty making the connection between the two areas when needed. It was argued that many aspects of 'design thinking' are applicable not just to simulation, but to all of engineering. Elements of design thinking from the literature were reclassified into four categories: general education, engineering, design, and analysis. Several additional types of engineering 'thinking' 


\section{Thompson}

were also added to the lists. Ultimately, the distinction between design and analysis may be doing more harm than good in the context of engineering education. After all, both activities are interrelated and critical to the professor. Perhaps students would benefit from a greater understanding of the connection.

Table 3. Categorizing 'Thinking' by Discipline

\begin{tabular}{|c|c|c|c|}
\hline General Education & Science / Engineering & Design & Simulation \\
\hline Ability to work in teams & $\begin{array}{l}\text { Ability to communication in the } \\
\text { multiple languages of engineering }\end{array}$ & Divergent - Convergent Thinking & Convergent Thinking \\
\hline \multirow[t]{9}{*}{ Critical Thinking } & $\begin{array}{l}\text { Ability to identify the 'real' } \\
\text { problem }\end{array}$ & Constructionist Thinking & Determinist Thinking \\
\hline & $\begin{array}{c}\text { Ability to make engineering } \\
\text { decisions }\end{array}$ & Synthetic Thinking & Analytical Thinking \\
\hline & $\begin{array}{c}\text { Ability to make engineering } \\
\text { estimates }\end{array}$ & Functional Thinking & Physical Thinking \\
\hline & $\begin{array}{c}\text { Ability to tolerate ambiguity and } \\
\text { uncertainty }\end{array}$ & Systems Thinking & Systems Thinking \\
\hline & $\begin{array}{l}\text { Ability to conduct scientific } \\
\text { experiments }\end{array}$ & $\begin{array}{l}\text { Ability to resolve conflict and } \\
\text { resist compromise }\end{array}$ & Ability to handle compromise \\
\hline & & Solution Neutral Thinking & $\begin{array}{l}\text { Ability to make assumptions and } \\
\text { simplifications }\end{array}$ \\
\hline & & $\begin{array}{l}\text { Techno-Socio-Economic } \\
\text { Thinking }\end{array}$ & $\begin{array}{l}\text { Ability to recognize assumptions } \\
\text { and simplications from others }\end{array}$ \\
\hline & & $\begin{array}{c}\text { Price Based (vs. Cost Based) } \\
\text { Thinking }\end{array}$ & $\begin{array}{l}\text { Ability to evaluate assumptions } \\
\text { and results }\end{array}$ \\
\hline & & $\begin{array}{c}\text { Top Down (Not Bottom Up) } \\
\text { Thinking }\end{array}$ & \\
\hline
\end{tabular}

\section{ACKNOWLEDGMENTS}

The author would like to acknowledge Dr. John M. Thompson for his many years of collaboration on the simulation courses discussed in this work; Prof. Taesik Lee and the entire ED100 faculty and staff for their help and support with the KAIST Freshman Design Program; and Ms. Yun-Hee Jung for her help in analyzing the data for this paper.

\section{REFERENCES}

Altshuller, G. 2005. 40 Principles Extended Edition: TRIZ Keys to Technical Innovation. Technical Innovation Center, Worcester, MA.

Beitz, W. 1994. Design Science - The Need for a Scientific Basis for Engineering Design Methodology. Journal of Engineering Design, 5: 2:129-133.

Dym C. L., Agogino, A. M., Eris, O., Frey, D. D., and Leifer, L. J. 2005. Engineering Design Thinking, Teaching, and Learning. J. Eng. Educ., Jan: 103-120.

Grinter, L.E. 1956. Report on the Evaluation of Engineering Education. Engineering Education, 46: $25-63$.

National Science Foundation. 1990. Engineering Education Coalitions (NSF89-107) Program Solicitation.

Lu, S. C. 2007. What is Design and Design Thinking? Design Thinking Lecture Series, KAIST Institute for the Design of Complex Systems, Daejeon, S. Korea.

Pahl, G., and Beitz, W., 1995. Engineering Design: A Systematic Approach (1st Ed.). Springer, London. 
Seymour, E. and Hewitt, N. Talking About Leaving. Factors contributing to high attrition rates among science, mathematics \& engineering undergraduate majors: final report to the Alfred P. Sloan Foundation on an ethnographic inquiry at seven institutions, 1994. University of Colorado.

Sheppard, S. D. 2001. The Compatibility (or Incompatibility) of How we Teach Engineering Design and Analysis. Int. J. Engng Ed. 17: 4 and 5: 440-445.

Sheppard, S. D., and Jenison, R. 1997. Freshmen engineering design experiences: an organizational framework. Int. J. Eng. Educ., 13,:3:190-197.

Suh, N. P., 1990. The Principles of Design. Oxford University Press, Oxford.

Thompson, M. K. 2009. ED100: Shifting Paradigms in Design Education and Student Thinking at KAIST. In Proceedings of the 2009 CIRP Design Conference.

Thompson, M. K.. 2009. Teaching Axiomatic Design in the Freshman Year: A Case Study at KAIST, In Proceedings of the 5th International Conference on Axiomatic Design.

Turner, M. J., Clough, R. W., Martin, H. C., and Topp, L.J. 1956. Stiffness and deflection analysis of complex structures. $J$ Aero Sci 23: 805-823.

\section{AUTHOR BIOGRAPHIES}

MARY KATHRYN THOMPSON is an Assistant Professor in the Civil and Environmental Engineering Department at the Korea Advanced Institute of Science and Technology (KAIST). She received her Ph.D. in Mechanical Engineering from the Massachusetts Institute of Technology (MIT). She is the Director of the KAIST Freshman Design Program and is also working on a textbook for Engineering Analysis. Her email address is $<$ mkt@kaist.edu $>$. 